\title{
Screening of grated cheese authenticity by nir spectroscopy
}

\author{
Chiara Cevoli, Angelo Fabbri, Alessandro Gori, Maria Fiorenza Caboni, \\ Adriano Guarnieri
}

\author{
Department of Agricultural and Food Science, University of Bologna, Italy
}

\begin{abstract}
Parmigiano-Reggiano (PR) cheese is one of the oldest traditional cheeses produced in Europe, and it is still one of the most valuable Protected Designation of Origin (PD0) cheeses of Italy. The denomination of origin is extended to the grated cheese when manufactured exclusively from whole Parmigiano-Reggiano cheese wheels that respond to the production standard. The grated cheese must be matured for a period of at least 12 months and characterized by a rind content not over 18\%. In this investigation the potential of near infrared spectroscopy (NIR), coupled to different statistical methods, were used to estimate the authenticity of grated Parmigiano Reggiano cheese PD0. Cheese samples were classified as: compliance PR, competitors, non-compliance PR (defected PR), and PR with rind content greater then $18 \%$. NIR spectra were obtained using a spectrophotometer Vector 22/N (Bruker Optics, Milan, Italy) in the diffuse reflectance mode. Instrument was equipped with a rotating integrating sphere. Principal Component Analysis (PCA) was conducted for an explorative spectra analysis, while the Artificial Neural Networks (ANN) were used to classify spectra, according to different cheese categories. Subsequently the rind percentage and month of ripening were estimated by a Partial Least Squares regression (PLS). Score plots of the PCA show a clear separation between compliance PR samples and the rest of the sample was observed. Competitors samples and the defected PR samples were grouped together. The classification performance for all sample classes, obtained by ANN analysis, was higher of $90 \%$, in test set validation. Rind content and month of ripening were predicted by PLS a with a determination coefficient greater then 0.95 (test set).

These results showed that the method can be suitable for a fast screening of grated cheese authenticity.
\end{abstract}

Correspondence: Chiara Cevoli, Department of Agricultural and Food Science, University of Bologna, P.zza Goidanich n.60 - 47521, Cesena (FC). E-mail:chiara.cevoli3@unibo.it

Key words: Parmigiano Reggiano cheese, NIR spectroscopy, artificial neural network, multivariate statistics.

(C) Copyright C. Cevoli et al., 2013

Licensee PAGEPress, Italy

Journal of Agricultural Engineering 2013; XLIV(s2):e53

doi:10.4081/jae.2013.s2.e53

This article is distributed under the terms of the Creative Commons Attribution Noncommercial License (by-nc 3.0) which permits any noncommercial use, distribution, and reproduction in any medium, provided the orig-

\section{Introduction}

Parmigiano-Reggiano (P-R) cheese is one of the oldest traditional cheeses produced in Europe, (Zannoni, 2010). It carries the prestigious appellation of Protected Denomination of Origin (PD0), and the production is regulated by the Parmigiano-Reggiano Cheese Consortium (CFPR)

The denomination of origin is extended to grated P-R cheese made exclusively with whole cheese. The grating operation must occur in the defined geographical area of cheese production, and packaging must take place immediately, without any processing or addition of substances to modify the conservation and the original organoleptic characteristics. The grated cheese must be characterized by the absence of additives, moisture no less than $25 \%$ and no more than $35 \%$, matured for a period of at least 12 months, rind not over 18\%, typical amino-acid composition of the cheese, not crumbly in aspect and with homogeneous particles with a diameter inferior to $0.5 \mathrm{~mm}$ and not exceeding 25\% (D.P.C.M. 4/11/1991), in addiction to the specific rules and compliance to the standard that local processors must attain to during production.

Therefore, to guarantee the quality and authenticity of grated P-R, it is important to monitor the preparation of the grated product in the diary factories. Food frauds and deceptive practices, carried out by unscrupulous producers solely oriented to the misrepresentation, have always been a serious problem because of the economic advantages deriving from partial replacement of high-priced ingredients with low cost ones. In particular, for foodstuffs produced, processed and prepared in a specific geographical area using recognized methods, objective and exhaustive food authenticity information is the major concern for food producers, retailers and consumers, against fraudulent practices. The main concern during the cheese grating operations, is the loss of the stamp embossed on the rind as a symbol of authenticity and guarantee to costumers, that will be printed afterwards on the package. In this way, the grated P-R can be easily mixed with low quality cheeses, extra rind and non-compliant P-R samples

The traditional analysis to discriminate P-R cheese from others brands of hard cheese, are based on the determination by wet chemistry of some technological parameters (Panari et al., 2009).

More efficient but expensive spectroscopic techniques to determine the authenticity of Parmigiano Reggiano cheese are stable isotope analysis and nuclear magnetic resonance (Consonni and Cagliani, 2008; Camin et al., 2012).

To determine the rind percentage and the months of ripening of the grated P-R by referring only to moisture value of the product is difficult because the packs are filled with grated cheese from different areas of the wheel. The cheese making technology and the dimension of the wheel (22-24 cm high, 40-45 cm diameter) of this long-ripened cheese (minimum 12 months of ripening) lead to differential evolution of the chemical /physical parameters between the inner and the outer zones during the ripening (Malacarne et al., 2009; Tosi et al., 2008; De Dea Lindner et al., 2008; Panari et al., 2003; Careri et al., 1996; Pecorari et al., 1995). 
The possibility of detecting the addition of extra rind to grated cheese (Grana Padano) and the ripening time of the P-R cheese has been studied by means of destructive chemical methods (Cattaneo et al., 2008; Consonni et al., 2008; Shintu and Caldarelli, 2005).

It therefore becomes important to find a method to determine authenticity, rind percentage, and months of ripening of the grated $\mathrm{P}$ $\mathrm{R}$ cheese based on a non destructive, fast and high-throughput techniques. In this way the infrared spectroscopy (IR) combined with the chemiometric technique, can be represent a good alternative (Reid et al., 2006; Luykx and van Ruth, 2008). With regards to near infrared spectroscopy (NIR), investigations combined with chemometric methods were carried out for cheese authentication (Pillonel et al., 2003; Ottaviana et al., 2012), prediction of sensory attributes (GonzálezMartín et al.2011), and determination of physicochemical properties of cheese ( Karoui et al., 2003; Karoui et al., 2006; Sánchez-Macías et al., 2010).

The present research intends to investigate the potential of the use of NIR coupled to different chemiometric techniques to discriminate grated P-R cheese from non-compliance P-R (defected P-R; P-R with rind $>18 \%$ ) and competitors and to predict the rind percentage and months of ripening of the grated P-R.

\section{Materials and methods}

\section{Samples}

For the experimentation 400 grated cheese samples classified as compliance P-R, competitors, non-compliance P-R (defected P-R) and $\mathrm{P}-\mathrm{R}$ with rind content $>18 \%$ were used.

Compliance P-R samples (140) derived from certified whole cheese wheels, grated and packaged in the area of origin as quoted in the product specification (D.P.C.M. 4/11/1991).

Non-compliance P-R, were grated samples derived from certified whole cheese wheels, but characterized by the presence of extra rind content varying from $25 \%$ to $50 \%$ (106). A further class of non-compliance P-R was represented by the grated cheese samples derived from defected uncertified whole P-R cheese wheels (38). The compliance and non-compliance grated P-R cheese samples were of known month of ripening (from 12 to 32 circa), and provided by the CFPR which guaranteed the origin.

The competitor group (116) was composed by commercial brands of Italian, European and extra-European grated cheeses of unknown age, collected at local markets.

Particle size of the samples ranged between 0.5 and $1.5 \mathrm{~mm}$.

\section{NIR spectroscopy}

NIR spectra were obtained using a spectrophotometer Vector 22/N (Bruker Optics, Ettlingen, Germany) in diffuse reflectance mode. The instrument was equipped with a rotating integrating sphere that allows a wide illumination of the sample and a better reduction of scattering due to the irregularity of the surfaces. Before every analysis, each box containing grated cheese was stirred. NIR spectrum was obtained by average of 32 scans of each sample and three replicates were collected for each individual sample (50 $\mathrm{g}$ of grated cheese) by using standard cups with quartz base. Background was defined by acquiring the spectrum of the quartz support without the sample, in the same instrumental conditions $\left(25^{\circ} \mathrm{C}\right)$. The speed of acquisitions was $10 \mathrm{kHz}$ in a range from $12500 \mathrm{~cm}^{-1} 4000 \mathrm{~cm}^{-1}$ to and $8 \mathrm{~cm}^{-1}$ of spectral resolution

\section{Data processing}

To remove the effects of light scatter, NIR spectra were pre-treated with multiplicative scattering correction (MSC). Data were also treated by applying the first derivative (Savitsky-Golay) to the absorbance data. Mean-centred spectral data were subjected to PCA, ANN and PLS analysis.

Principal component analysis (PCA) was applied as an exploratory analysis in order to define a possible discrimination between samples of compliance P-R and non-compliance P-R or competitors and based on rind percentage and months of ripening (The Unscrambler ver. 9.7, CAMO, Oslo, Norway).

To discriminate among specific classes, artificial neural network models (ANN) were performed by using STATISTICA Neural Networks 4.0 (StatSoft Inc., Tulsa, OK, USA). A Multi-Layer Perceptron (MLP) neural network was built to predict the specific classes to which the samples belong. To perform classification tasks, four nominal output variables (I, II, III and IV) were used: I for compliance P-R samples, II for competitors samples, III for defected P-R samples (not-compliance) and IV for P-R samples with a rind percentage higher than $18 \%$ (noncompliance). For input and hidden layers, linear and logistic activation function were used, respectively, while for output layer the softmax function was used. From a statistical point of view, with the softmax activation function and the cross-entropy error, neural network model can be seen as a multilogistic regression model, and the outputs are then interpretable as posterior probabilities for categorical target variables (Bishop, 1995).

Looking for the best classification ability, different node numbers in the hidden layer and combinations of momentum and learning rate were tested. The convergence of ANNs was ruled by a back propagation algorithm. The original datasets were randomly divided into training set (70\%), verification set (15\%) and test set (15\%). It was checked that samples from all classes were contained in the test set.

Subsequently two Partial Least Squares regression (PLS) models were built to predict the rind percentage and the month of ripening from the NIR spectra of the samples. Particularly for the prediction of months of ripening, only the spectra of compliance P-R samples were used. The models were calibrated using $80 \%$ of the data set, selected as representative of the population variance, and validated by means of leave-one-out full cross validation and test set validation (performed using the remaining $20 \%$ of the data set).

\section{Results}

The score plot of the PCA performed to discriminate between compliance P-R, competitors and defected P-R samples is reported in Figure 1. A clear separation between compliance P-R samples and the others samples was observed. Defected P-R and competitors samples were grouped together. It can be see that both the PC1 (89\%) and the PC2 (3\%) contributed to the discrimination. that might be attributed to spectral regions that previous investigations associated with moisture and lipid contribution (Karoui et al., 2005 and 2006). Furthermore, during the ripening, complex chemical-physical modification might occur: particularly proteolysis and lipolysis are the most important biochemical processes, which cause a variation in the state of the nitrogen fraction as well as a modification of the lipid composition (Pellegrino et al., 1997; McSweeney, 2004; Tosi et al., 2008).

The score plot concerning the discrimination between samples characterized by different rind percentage, is reported in Figure 2 . The technique was unable to achieve a clear separation between samples with different rind percentage. Only the samples characterized by a rind 
content $18 \%$ were grouped. An insufficient separation may be due to the fact that in addition to the rind percentage, also the months of ripening varied (from 12 to 32 months).

Considering only the compliance samples (rind content $<18 \%$ ), it is possible to observe for both spectroscopic techniques (Figure 3) that the samples distribution take place according to the months of ripening. Particularly, the samples with less than 17 months of ripening and the sample with more than 27 months of ripening are grouped separately.

Concerning the ANN results, an early stopping technique was used to select the number of training cycles to avoid overfitting, using the verification set to monitor the prediction error. The learning rate and momentum parameters were used to control the size of weight adjustment along the descending direction and for dampening oscillations of the iterations.

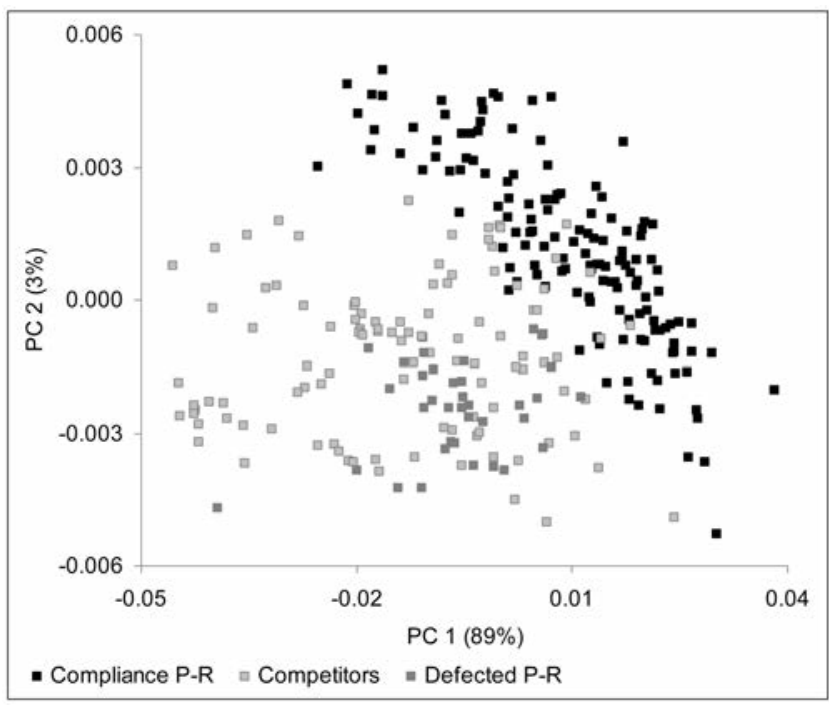

Figure 1. Score plot obtained by PCA analysis to discriminate the compliance P-R from non compliance (competitors and defected $P$.

Table 1. Classification results obtained by artificial neural network (ANN).

\begin{tabular}{lccc} 
Classes & \multicolumn{2}{c}{$\begin{array}{c}\text { Corrected classified cases (\%) } \\
\text { Validation set }\end{array}$} & $\begin{array}{l}\text { Test set } \\
\text { Compliance P-R }\end{array}$ \\
Competitors & 100 & 100 & 95.5 \\
\hline Defected P-R & 100 & 95.5 & 95.5 \\
Rind $>18 \%$ & 100 & 100 & 100 \\
\hline
\end{tabular}

Table 2. Prediction results obtained by Partial Least Squares regression models (PLS).

\begin{tabular}{llccc} 
& & PCs & $\mathrm{R}^{2}$ & RMSE \\
Rind (\%) & Calibration & 15 & 0.982 & 1.473 \\
& Cross validation & 15 & 0.953 & 2.227 \\
& Test set & 13 & 0.95 & 2.319 \\
Months of ripening & Calibration & 14 & 0.986 & 0.805 \\
& Cross validation & 14 & 0.95 & 1.491 \\
& Test set & 12 & 0.942 & 1.562 \\
\hline
\end{tabular}

Note: PCs, number of Principal Component; $\mathrm{R}^{2}$, determination coefficient; RMSE, Root Mean Square Error.
The power of the classification model was evaluated by using three parameters: (I) classification ability: percentage of correctly classified samples in both training, verification and test sets; (II) recognition ability: percentage in the training and verification set; (III) predictive ability: percentage of correctly classified samples in the test set during the training step (Cajka et al., 2009).

In Table 1 are reported the results of the neural networks tested to discriminate the compliance P-R, the competitors, the defected P-R and $\mathrm{P}-\mathrm{R}$ with rind content $>18 \%$.

The best prediction results were obtained with a three layer network, having 5 nodes in the hidden layer. A large number of nodes did not increase the network performance. All the ANNs were obtained with a learning rate of 0.01 and a momentum of 0.8 .

The classification, recognition and predictive ability were $98.5,97$, 100 and $97 \%, 100,97.8,100$ and $100 \%$ and $95.595 .5,100$, and 91\%,

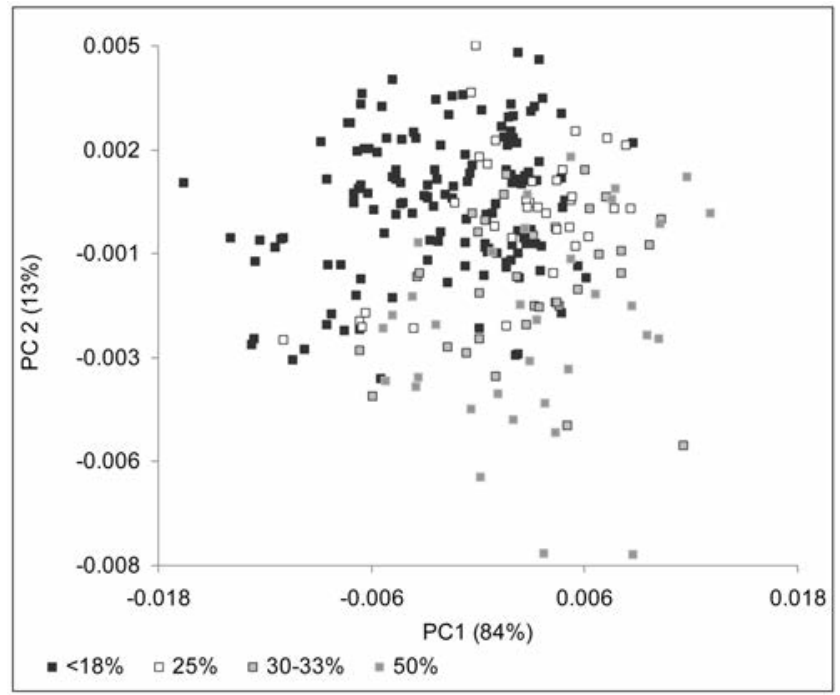

Figure 2. Score plot obtained by PCA analysis (compliance P-R and P-R with rind $>18 \%$ ) to discriminate the rind percentage.

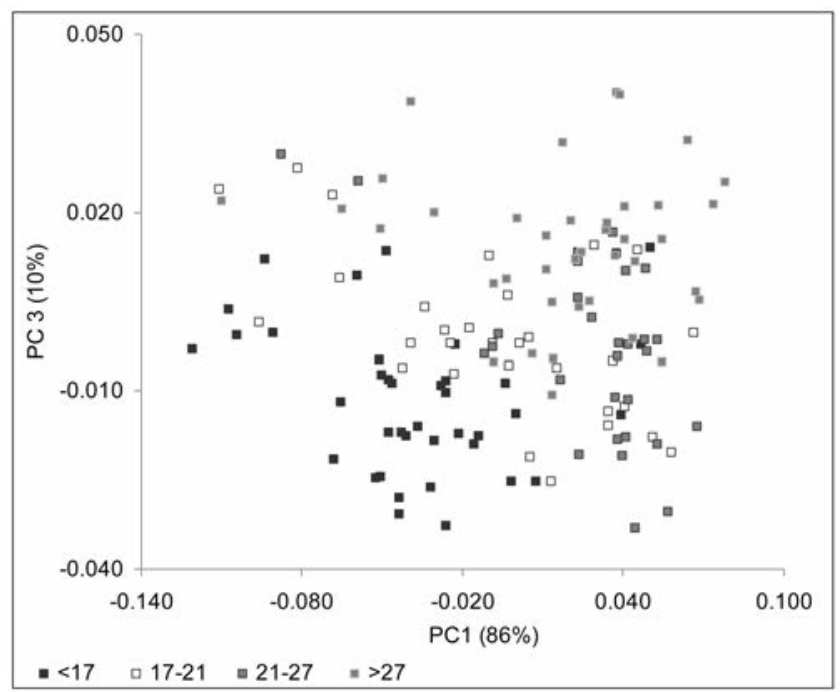

Figure 3 .Score plot obtained by PCA analysis of the compliance P-R spectra to discriminate the months of ripening. 
respectively for compliance P-R, competitors, defected P-R and P-R with rind content $>18 \%$.

The results of the PLS analysis, in terms of determination coefficient $\left(\mathrm{R}^{2}\right)$ and root mean square error (RMSE) in calibration, cross validation e test set validation were reported in Table 2 .

For all data sets, it can be seen that the rind percentage is predicted by a $\mathrm{R}^{2}$ greater than 0.95 and a maximum RMSE of about $2.4 \%$ (test set validation), while months of ripening, by a $\mathrm{R}^{2} 0.942$ and a maximum RMSE of 1.562 months (test set validation). The exact rind percentage of the compliance P-R samples was not known, in fact these samples were characterized by a rind percentage between $12 \%$ and $18 \%$. Consequently a not accurate reference data can be negatively influence the results.

\section{Conclusions}

Near infrared spectroscopy coupled with advanced statistical techniques (PCA and ANN), were able to discriminate in a fast and reliable way the grated samples of the PDO P-R cheese from major commercial brands of competitors and from non-compliance P-R (samples with extra rind content or defect). ANN resulted to be able to classify correctly in the test set the $95.5 \%$ of compliance.

Rind content and month of ripening were predicted by PLS analysis with a determination coefficients in test set validation of 0.95 (RMSE= 2.4\%) and 0.942 (RMSE=1.562 months), respectively.

The results obtained confirms the use of spectroscopic as method suitable for a fast screening of grated cheese authenticity.

\section{References}

Bishop C.M., 1995. Neural Networks for Pattern Recognition. Oxford University Press, Oxford, UK.

Cajka T., Hajslova J., Pudil F., Riddellova K. 2009. Traceability of honey origin based on volatiles pattern processing by artificial neural networks. J. Chromatogr. A. 1216:1458-1462.

Camin F., Wehrens R., Bertoldi D., Bontempo L., Ziller L., Perini M., Nicolini G., Nocetti M., Larcher R. 2012. H, C, N and S stable isotopes and mineral profiles to objectively guarantee the authenticity of grated hard cheeses. Anal. Chim. Acta. 711:54-59.

Careri M., Spagnoli S., Panari G., Zannoni M., Barbieri, G. 1996. Chemical Parameters of the Non-volatile Fraction of Ripened Parmigiano-Reggiano Cheese. Int. Dairy J., 6:147-155.

Cattaneo S., Hogenboom J.A., Masotti F., Rosi V., Pellegrino L., Resmini P. 2008. Grated Grana Padano cheese: new hints on how to control quality and recognize imitations. Dairy Sci. Technol. 88:595-605.

Consonni R., Cagliani L.R. 2008. Ripening and geographical characterization of Parmigiano Reggiano cheese by 1H NMR spectroscopy. Talanta, 76:200-205.

Council Regulation (EC) $n^{\circ} 510 / 2006$, On the protection of geographical indications and designations of origin for agricultural products and foodstuffs. Official Journal of the European Union, 93:12-25.

D.P.C.M. 4/11/1991. Estensione della denominazione di origine del formaggio «Parmigiano Reggiano» alla tipologia «grattugiato». Gazzetta Ufficiale, n. 83, 8 /4/1992.

De Dea Lindner J., Bernini V., De Lorentiis A., Pecorari A., Neviani E. Gatti M. 2008. Parmigiano Reggianocheese: evolution of cultivable and total lactic microflora and peptidase activities during manufacture and ripening. Dairy Sci. Technol. 88:511-523.
González-Martín M.I., Severiano-Pérez P., Revilla I., Vivar-Quintana A.M., Hernández-Hierro J.M., González-Pérez C., Lobos-Ortega I.A. 2011. Prediction of sensory attributes of cheese by near-infrared spectroscopy. Food Chem. 127: 256-263.

Karoui R., Mouazen A. M., Dufour E., Pillonel L., Schaller E., de Baerdemaeker J., Bosset J. 0. 2006. Chemical characterisation of European emmental cheeses by near infrared spectroscopy using chemometric tools. Int Dairy J. 16:1211-217.

Karoui R., Dufour E., Pillonel L., Schaller E., Picque D., Cattenoz T. 2005. The potential of combined infrared and fluorescence spectroscopies as a method of determination of the geographic origin of Emmental cheeses. Int Dairy J. 15:287-298.

Karoui R., Mazerolles G., Dufour E. 2003. Spectroscopic techniques coupled with chemometric tools for structure and texture determinations in dairy products: a review. Int Dairy. 13:607-62.

Luykx D.M.A.M., \& van Ruth S.M. 2008. An overview of analytical methods for determining the geographical origin of food products. Food Chem. 107:897-911.

McSweeney P.L.H. 2004. Biochemistry of cheese ripening. Int. Dairy J. 57:127-144.

Malacarne M., Summer A., Franceschi P., Formaggioni P., Pecorari M., Panari G., Marian P. 2009. Free fatty acid profile of ParmigianoReggiano cheese throughout ripening: comparison between the inner and outer regions of the wheel. Int Dairy J. 19:637-641.

Panari G., Filippi S., Caroli A., Pecorari A., Nocetti M. 2009. Analytical methods to distinguish Parmigiano-Reggiano cheese from similar varieties of cheese. Scienza e Tecnica Lattiero-Casearia, 60:25-29.

Panari G., Mariani P., Summer A., Guidetti R., Pecorari M. 2003. Variazione della composizione e andamento della proteolisi del Parmigiano-Reggiano nel corso della maturazione in riferimento al profilo (centro e periferia) della forma. Scienza e Tecnica Lattiero Casearia, 54:199-212.

Pecorari A., Gambini G., Panar, G., Nocetti M. 2007. The characterisation of 12 months old Parmigiano-Reggiano cheese. Scienza e Tecnica Lattiero Casearia, 58:205-217.

Pellegrino L., Battelli G., Resmini P., Ferranti P., Barone F., Addeo F. 1997. Effects of heat load gradient occurring in moulding on characterization and ripening of Grana Padano. Lait, 77:217-228.

Pillonel L., Luginbühl W., Picque D., Schaller E., Tabacchi R., Bosset J 0. 2003. Analytical methods for the determination of the geographic origin of Emmental cheese: mid- and near-infrared spectroscopy. Eur Food Res Technol, 216:174-178.

Reid L.M., O'Donnell C.P., Downey G. 2006. Recent technological advances for the determination of food authenticity. Trends Food Sci Tech, 17:344-353.

Sánchez-Macías D., Fresno M., Moreno-Indias I., Castro N., MoralesdelaNuez A., Álvarez S., Argüello A. 2010. Physicochemical analysis of full-fat, reduced-fat, and low-fat artisan-style goat cheese. J Dairy Res, 9:3950-3956.

Savitzky A., Golay M.J.E. 1964. Smoothing and differentiation of data by simplified least-squares procedures. Anal Chem, 36:1627-1639.

Shintu L., Caldarelli S. 2005. High-Resolution MAS NMR and Chemometrics: Characterization of the Ripening of Parmigiano Reggiano Cheese. J. Agric. Food Chem. 53:4026-4031.

Tosi F., Sandri S., Tedeschi G., Malacarne M., Fossa E. 2008. Variazione di composizione e proprietà fisico-chimiche del Parmigiano Reggiano durante la maturazione e in differenti zone della forma. Scienza e Tecnica Lattiero Casearia, 59:507-528.

Zannoni M. 2010. Evolution of the sensory characteristics of Parmigiano-Reggiano cheese to the present day. Food Qual Pref. 21:901-905. 